Copyright statement:

This is post-print version of the following article: Ciesla, K., loannou, M., \& Hammond, L. (in press). Women offenders' emotional experience of crime. Journal of Investigative

Psychology and Offender Profiling ISSN 15444759 (Forthcoming)

This article may be used for non-commercial purposes in accordance With Wiley Terms and Conditions for self-archiving. 


\title{
Women Offenders' Emotional Experience of Crime
}

\author{
Kayley Ciesla $^{1 *}$, Maria Ioannou ${ }^{2}$, and Laura Hammond ${ }^{3}$ \\ ${ }_{1}$ Kayley Ciesla, International Research Centre for Investigative Psychology, \\ Department of Psychology, School of Human and Health Sciences, University \\ of Huddersfield, Queensgate, Huddersfield HD1 3DH, UK \\ Email: kayley.ciesla@hud.ac.uk
}

Mobile: $+44(0) 7932970222$

${ }_{2}$ Maria Ioannou, International Research Centre for Investigative Psychology, Department of Psychology, School of Human and Health Sciences University of Huddersfield, Queensgate, Huddersfield HD1 3DH, UK. Email:

m.ioannou@hud.ac.uk

Mobile: +44 (0) 7796123044

${ }_{3}$ Laura Hammond, Department of Psychology, Faculty of Business, Law and Social Sciences, Birmingham City University, City Centre Campus, Curzon 415, 4 Cardigan Street, Birmingham, B4 7BD, UK.

Email: laura.hammond@bcu.ac.uk

Phone: + 44 (0) 1213317263

*Corresponding author 
Emotions and Crime

\begin{abstract}
The main aim of the study was to examine the emotional experiences of crime amongst women offenders. 128 women offenders, with a mean age of 36.40 years $(S D=11.12)$, completed a questionnaire exploring emotions they had experienced whilst committing a crime. Participants included incarcerated individuals as well as those in community-based projects. Smallest Space Analysis of the emotions highlighted four key themes; Depression, Distress, Elation and Calm. Results reflected the circumplex model of emotions (Russell, 1997), but highlighted strong distinction between pleasure and displeasure. Overall, the majority of women reported negative emotional experiences of crime. Understanding how individuals felt during their crime commission, offers alternative perspectives of criminal behaviour and a framework for future explorations. Results offer crucial insights for policy makers, criminal investigations and therapeutic treatment options.
\end{abstract}

Key words: Women offenders, emotions and crime, offender typologies. 
Emotions and Crime

\section{Women Offenders}

Historically, theories of crime were largely developed based on male samples and applied to women as an afterthought, ignoring variations and women specific factors involved in offending (Cook, 2016). However, in recent years various areas of work have been undertaken exploring routes into criminality from a gendered perspective. Such research has highlighted significant differences between the way men and women interact with the world, and as a result the impact this has on offending motivations and behaviours (Chesney-Lind \& Pasko, 2004; Daly, 1992).

Research has consistently highlighted that women have distinct and multiple needs that need to be acknowledged when exploring criminal motivations, including substance abuse, mental health, victimisation, traumatic childhoods and abuse (Bloom, Owen \& Covington, 2003; Corston, 2007; Covington \& Bloom 2006; de Vogel, de Vries-Robbe, Van Kalmthout \& Place, 2012; Rossegger et al., 2009; Salisbury, 2007; Scott \& Dedel, 2006). However, whilst feminist research has demonstrated that the aetiology of female offending is unique, gender-neutral researchers (Andrews \& Bonta, 2010; Andrews et al., 2012; Gendreau, Smith \& French, 2006) argue theories of criminal behaviour are equally applicable to the sexes (Jones, Brown, Wanamaker, \& Greiner, 2014). Whilst it can be argued that there are commonalities amongst offending behaviours between men and women, growing evidence does suggest that gendered approaches to developing theories of offending are crucial.

\section{Phenomenological Experiences of Crime}

There are numerous theoretical stances that have attempted to provide explanations of crime across a range of disciplines. However, one area that has generally been 
Emotions and Crime

neglected is the experience of the offender themselves. This is an area of invaluable insight, as who can be more of an expert as to why one offends, than the offender themselves? Katz (1988), highlighted this misnomer and states criminal behaviours cannot possibly be understood or explained, without grasping how it is experienced or what it means to the actor. He proposed that emotional significance of crimes needed to be considered further, to allow deeper psychological understanding of the processes that lead individuals to engage in crime. The value of a phenomenological approach in relation to exploring offender experiences has been utilised in a range of studies (Blagden, Winder, Thorne \& Gregson, 2011; Facchin \& Margola, 2016; Jackson-Roe, Murray \& Brown, 2015). The importance of emotions and women offender's individualistic experiences of crime will be explored further in this study.

\section{The Importance of Emotions}

The American Psychological Association (2018), defines emotion as 'a complex pattern of changes, including physiological arousal, feelings, cognitive processes, and behavioral reactions, made in response to a situation perceived to be personally significant' (https://dictionary.apa.org/emotion). Although this definition gives a basic overview, operationally it is not sufficient to account for the complexities involved in defining, predicting and exploring emotions. There is much debate over the nature of emotions and many have theorised about the development, effects, subjectivity and familiarity of these feelings without conclusive agreement on what such attributes are (Daly, Lancee \& Polivy, 1983; Plutchik, 1962).

Emotions are of fundamental importance and involved in every aspect of human interaction, emotions influence decisions and are at the centre of every individual's 
Emotions and Crime

mental processing (Oatley \& Jenkins, 1996). Emotions are responsible for all communications and are not only related to the present but develop from past experiences and influence anticipated future communications. Emotions can be both automatic and controlled, whilst also being a result of reflective judgements based on understanding and analysis of situations (Jarymowicz, 2012). Explorations by Katz (1999), highlight that understanding how a person responds emotionally defines the uniqueness of who that person is.

\section{Dimensionality of Emotions}

Classifying affective structure in early research favoured monopolar explanations, suggesting discrete and separate dimensions of emotional experience, postulating six to twelve independent factors of emotion, including degrees of sadness, elation, anger, and anxiety to name a few (Daly et al., 1983; Izard, 1972). However, methodological flaws such as limited sample sizes and lack of ecological validity have been highlighted in such approaches and alternative explanations are now preferred (Russell, 1978). Generally favoured is the bipolar dimensionality of emotions, suggesting dimensions are related to each other in a systematic manner rather than being independent of each other (Mehrabian \& Russell, 1974; Russell, 1978; Daley et al, 1983). Two dimensions proposed PleasureDispleasure (include emotions such as happiness/content and opposing emotions such as sadness/fear), and Degree of Arousal (excited versus relaxed) have been established as two main measurements of mood (Watson \& Tellegen, 1985). Several studies have replicated the presence of two bipolar dimensions in explaining emotionality, including analyses of facial and vocal emotional expressions (Ableson \& Sermat, 1962; Schlosberg, 1954), varying ratings of mood expressions (Averill, 1975) and cross culturally among athletic populations (Loizou, \& Karageorghis, 2015). 
Emotions and Crime

There has been dispute from other theorists suggesting three dimensional models offer a better explanation to include, Dominance-Submissiveness along with PleasureDispleasure and Arousal (Russell \& Mehrabian, 1977), however such a model could not be replicated cross-culturally and only accounted for a very minor amount of variance (Russell, 1978, 1983). Therefore, as there is a substantial amount of empirical research that supports the bipolar dimensionality of emotions this approach is preferred.

\section{The Circumplex of Emotions}

Russell (1980, 1997), takes the concept of dimensionality further and suggests that it is more beneficial to view emotions and feelings in a circular order, a circumplex, whereby all emotional states merge into one another around the perimeter of the circumplex. The areas within the circumplex are defined by a bipolar valence (pleasantness) dimension and an orthogonal dimension labelled arousal. Valence refers to the degree of pleasantness of the emotions and arousal relates to the amount of activation. Within the circumplex adjacent categories that are the most similar e.g. startle and fear are more closely related than startle and anger, similarly emotions that are contrasting are further removed on the circle. Variables most similar in meaning are located in close proximity whereas opposite terms are at opposite sides of the circle. Consequently, as happy and sad are semantically opposite they are found on opposite areas of the circumplex. The centre of the circumplex is a neutral zone and the structure suggests a degree of variation in emotional intensity from the centre moving outwards, thus the further from the centre the more intense the variable becomes. Figure 1. highlights the schematic representation of the circumplex and identifies four main classes of mood: distress, elation, calmness and depression. 
Emotions and Crime

The notion of a circular archetype is part of a range of models based on Guttman's (1954), Facet Theory that have proven beneficial in explaining human behaviours (Canter, 1984). There is much research to support benefits of the circumplex model for categorising and explaining the structure of emotions (Carney \& Colvin, 2010; Feldman, 1995; Feldman Barrett \& Russell, 1998; Fisher, Heise, Borhnstedt \& Lucke, 1985; Fontanari, Bonniot-Cabanac, Cabanac \& Perlovsky, 2012; Loizou \& Karageorghis, 2015; Plutchik, 1962; Remington, Fabrigar \& Vissar, 2000; Russell, 1980; Schlosberg, 1941; Watson \& Tellegen, 1985).

Although there is wide support and evidence for the circumplex, one limitation of the model is that it cannot provide a full explanation of the emotional experience. For example, although the dimensionality captures the majority of affective experience it cannot explain aspects that present spontaneously due to physiological reasons. For example, when looking at the circumplex fear and anger are close together suggesting similarity in valence and arousal, however there are obvious differences between these two emotions in relation to willingness to act out which cannot be fully explained. Similarly, when a person falls in love or acts out of jealousy the two dimensions cannot fully explain such experiences. One other area the circumplex lacks is in relation to intensity, as emotions that appear to have low arousal may actually be quite powerful for an individual such as depression. However, despite the circumplex not being able to provide a complete understanding of all emotional experiences, the model accounts for the most significant aspects of emotionality and has been used successfully in a variety of cultures and studies with encouraging results (Plutchik, 2000). 
Emotions and Crime

\section{Emotions and Gender}

As discussed emotions are central to every human experience, but the distinctive and subjective experiences can vary from one person to the next depending on their individual interactions with the world. It has been suggested that men and women vary in their intensity and understanding of emotions (Brebner, 2003). Research has highlighted gender differences cross-culturally in relation to types of emotions experienced, men were found to report more powerful emotions such as anger, whereas women indicated more powerless emotions such as sadness and fear (Fischer, Rodriguez, Vianen \& Manstead, 2004). Similarly, explorations of occurrence of shame between men and women also highlighted gender differences. Women reported experiencing greater intensity and more negative emotions linked to pain in relation to feelings of shame, whereas men described shame as a necessity to conform to societal expectations but did not detail pain with this emotion (Norberg, 2012). Research by Chaplin \& Aldao, (2013), highlighted gender differences in relation to expression of emotion. Results indicated that women tended to internalise emotions (e.g., sadness, anxiety, sympathy) in comparison to men who were more likely to externalise their emotions (e.g., anger).

\section{Emotions and Crime}

As discussed, appreciation of the phenomenological experience of emotions are invaluable, Bernasco (2010), states offenders are 'experts' as they are the ones involved in criminal acts. It is therefore crucial that perceptions and experiences of crime are explored from the offenders' personal perspective. Katz's' (1988), important book Seductions of Crime, was probably the first significant exploration into emotions that individuals experience during crime. His research highlighted the wide range of emotional states utilised to entice offenders to initiate and sustain criminal acts. Similarly, 
Emotions and Crime

this premise is mirrored by Langton \& Marshall (2000), who state emotions have a persistent influence on offenders' motivations both prior to and during offence commission. Indermaur (1993), examined emotional experiences amongst violent property offenders, and asked individuals to indicate their thoughts and feelings before, during and after their offence. Findings indicated subjects described their emotions as justifiable anger or as being in an 'impossible situation'. Other studies have found emotions are fundamental in decision making whilst committing crimes (Wright, Decker, Redfern, \& Smith, 1999) and as viewing their lives as adventures and more exciting than those of the general public (Åkerström, 1999).

Preliminary research has been undertaken applying Russell's (1997) Circumplex to emotional experiences of offenders. Findings have highlighted that offenders who were asked to describe emotions they felt whilst committing a crime reflected those presented in the circumplex structure. One interesting finding in this research emphasised that individuals demonstrated a stronger distinction between pleasure and displeasure in comparison to normal non-criminal experiences (Canter \& Ioannou, 2004). Similarly, further research has replicated the full gamut of Russell's (1997), emotions amongst male offenders highlighting four main affective themes: Elation, Calm, Distress, and Depression (Canter \& Ioannou, 2004; Ioannou, 2006; Ioannou, Canter, \& Youngs, 2017).

Although findings are promising and provide a great starting point for future explorations the majority of studies were undertaken on incarcerated male offenders, and thus certain limitations must be acknowledged. As participants were incarcerated, this posits limitations in regard to representativeness of the general criminal population. Similarly, as discussed men and women tend to vary in their experiences of emotions, so 
Emotions and Crime

it is unclear whether such findings can be applied to women offenders. On balance however the Circumplex model offers a significant and convincing starting point for examining offender's experiences of crime.

\section{The Present Study}

As discussed there is an increasing body of evidence suggesting emotional experiences of crime can provide useful psychological frameworks for understanding a person's actions during the commission of a crime. The main aim of the current study therefore is an expansion on previous research amongst male offenders, and attempts to explore the experience of committing a crime amongst women offenders. The objectives of this study are outlined below:

1. To establish whether the overall structure of emotions experienced by women when committing crimes can be differentiated in terms of different emotion themes e.g. elation, calm, distress, depression.

2. To determine whether the circumplex of emotions established for non-criminal experiences (Russell, 1997) can be established for women offenders.

\section{METHOD}

\section{Sample}

Age. Participants in the current study consists of 128 women aged 18-70 years old who have committed a crime. Mean age of the sample is 36.40 years $(S D=11.12)$, with a median age of 35 . 
Emotions and Crime

Ethnicity. $89.10 \%$ of the sample questioned were White. The second largest ethnic groups were Pakistani and Indian which both accounted for $2.30 \%$ of the sample. These were followed by Black-African accounting for $1.60 \%$ of participants. Black-Caribbean and Bangladeshi were the next most prevalent ethnicities both accounting for $0.80 \%$ of the sample. The remaining $3.10 \%$ of the sample described themselves as of 'other' ethnic origin, as is displayed in Table 1.

Type and Number of Convictions. Table 2. highlights recalled offences and their frequency within the sample. Table 3. shows the number self-reported convictions from participants. More than half of the women (60.20\%) have less than 10 convictions, however $22.6 \%$ have between 10 and 50 convictions and $13.30 \%$ have more than 50 convictions. This split is likely to be due to the fact the there is a combination of incarcerated participants, and those in the community.

Recruitment of Participants. Participants were recruited from a variety of projects including prisons and community projects across the U.K. All participants volunteered to take part in the study, they were approached by either the researcher or their key worker/officer at the various sites to determine whether they were interested in taking part.

INSERT TABLE 1 HERE

INSERT TABLE 2 HERE 


\section{INSERT TABLE 3 HERE}

\section{Materials used for Data Collection}

A questionnaire was utilised in this study, participants were asked to complete two sections:

1. Description of Crime. This included a list of twelve questions enquiring about events leading up to commission of the crime, what occurred during the crime, anything they did to avoid arrest and what they did after the crime. The main purpose of this section was to enhance details of the crime participants were recalling, enabling better description of how they felt when committing such acts. Explaining the offence in detail would allow memories associated with the whole event to be stronger.

2. Emotions Statements. This section of the questionnaire included twentyfive statements signifying the full range of emotions highlighted by Russell's, (1997) circumplex. This was developed from previous research that examined convicted offenders' feelings when asked to describe the emotions they experienced whilst committing a crime they could clearly recall. Results highlighted clear emotions that were utilised to help participants make sense of their crimes and behaviour (Oldale, 1997; Cross, 1998; Murray, 1998; Canter \& Ioannou, 2004). Statements were rated on a five-point Likert scale which measured the extent to which participants experienced each emotion during commission of their crime, ratings ranged from, "Not at all" (1) to "Very much" (5) with "Some" (3), being the mid-point. Utilisation of such a scale allowed greater understanding of participants answers and the extent to which emotions were felt rather than just indicating whether the emotion was 
Emotions and Crime

present or not. Examples of statements included: "I felt lonely", "I felt enthusiastic", "I felt calm".

\section{Procedure}

Once participants had been recruited it was ensured at each site a quiet and confidential environment was utilised when undertaking completion of the questionnaires. Volunteers were brought into the room and the researcher explained the nature of the study, informing them that they were going to answer questions about their emotional experiences of crime. During discussions, it was made clear that involvement was completely voluntary and they had the right to withdraw at any point without having to provide a reason. The fact that the study was completely confidential, and the data would not be made available to any of their workers, legal, police/probation authorities was also emphasised.

The researcher emphasised that the questionnaire was completely anonymous to ensure the participants were as open and honest as possible in their answers whilst not worrying about authorities knowing about their responses. The researcher instructed participants to think of a crime they had committed, and they could remember clearly and then provide a clear description of this and complete the questionnaire. The women were left to freely recall events of the crime in line with the questions in the first part of the questionnaire.

The second part of the questionnaire involved reading through a list of emotions statements participants experienced during commission of the crime. Participants were 
Emotions and Crime

asked to indicate to what extent statements were reflective of how they felt at the time of the crime. Once the questionnaire had been completed, the researcher debriefed participants, thanked them for their help and answered any questions they had relating to the research.

\section{Analysis}

Smallest Space Analysis (SSA). Data in the study was analysed using SSA-I (Lingoes, 1973). Tziner defines Smallest Space Analysis as 'a non-metric multivariate scaling procedure that geometrically represents a 'correlation matrix' based on the order of the inter-correlations among variables' (Tziner 1987 p. 39). SSA is similar to other multidimensional scaling models such as factor and cluster analysis, however it strengthens visual representation of relationships. Moreover, it allows for comparison of every one of the variables to every other variable within the data set. This allows the researcher to study both the components within the domain, and also the relationships between the components to help make clearer inferences from the data studied and helps inform potential future hypotheses.

SSA is so called as it accounts for the smallest explanation of dimensionality, as it ranks original correlations rather than their absolute values (Guttman, 1968). The SSA program calculates and ranks in order the correlations between each item explored which are then presented in an association matrix displaying the correlation of each variable with each other. From this matrix coefficients are then used to present a visual representation of the data. Each point on the SSA graphic characterises the variables explored and is calculated by repeated comparison of the rank order of correlations with the distance between each point and their contrary relationship. Therefore, the closer the 
Emotions and Crime

rank orders of distance and correlation, the healthier the visual representation to the original data matrix. This has been described as lower 'stress', to enable lower 'stress' the process is repeated until least 'stress' is achieved. This 'stress' process is finalised by using a coefficient of alienation to highlight the degree to which each variable is linked to the other via their corresponding relationships on the plot, the smaller the coefficient of alienation the greater the correspondence to the original correlational data. A value of zero would be a perfect fit, and a coefficient smaller than 0.15 considered a good fit, and a coefficient between 0.15 and 0.20 reasonably good (Guttman, 1968). However, Borg \& Lingoes (1987), suggest that it is often too simplistic to determine how 'good' or 'bad' a representation is as other factors such as the number of variables, logical theory behind experimentation and error will have an impact. Therefore, within an SSA arrangement the closer the variables are within the visual representation the higher their correlation.

To further explore the variables that are plotted within the same region an approach called Facet Theory is utilised (Shye, 1978). This allows correlated variables to be explored further by postulating hypotheses to explain the nature of the relationship and add more depth and systematic investigation to strengthen empirical assertions. Therefore, variables within the same 'facet' will have a stronger correlation and be visually closer on SSA representation, whereas those that are not within the same facet group will be in a different region of the multidimensional space. The propinquity of variables is known as the 'regional hypothesis' stating that those facets with similar themes will be found in the same region of space, whereas points further away from a boundary will be more discrete. To expand further, once specific regions have been identified that correspond to a similar theme, boundary lines are often added to help define specific facets. 
Emotions and Crime

\section{RESULTS}

\section{Results of SSA Analysis on Emotions}

As discussed, emotions with similar underlying themes are more likely to be highly correlated therefore will be closer together in the SSA configuration. Each point on the plot, relates to a variable linked to each specific emotion explored. The twodimensional SSA has a Guttman- Lingoes coefficient of alienation 0.10149 in 24 iterations, showing a good fit between Pearson's coefficients of emotions variables and their corresponding geometric distances in the configuration. The two-dimensional representation was adopted as it highlighted a satisfactory coefficient of alienation. The projection of vector 1 by vector 2 of two dimensional space is displayed in Figure 2. Labels included in this depiction are summaries of the full questions, however full questions can be seen in Table 4. for ease of interpretation.

\section{INSERT FIGURE 2 HERE}

\section{INSERT TABLE 4 HERE}

\section{Themes of Emotions}

To explore the hypothesised structure of emotions the visual representation of the SSA configuration was examined. As previously stated the regional hypothesis suggests that variables with commonalities will be clustered in the same area of space, therefore areas that had several emotions in the same area were examined to establish any common themes. On examination of the plot, there are four distinct emotional themes. Once this 
Emotions and Crime

had been established further exploration was undertaken to examine the grouping of variables and determine whether a common theme could be identified for each of the four configurations. Emotions in the top left of the quadrant included: "angry", "irritated", "pointless" and "annoyed" as these labels all seemed to indicate levels of distress this was the chosen name for this regions theme. This process was repeated for all four quadrants and the four themes are presented below, along with case studies to illustrate the varying emotional experiences of participants.

Depression. The bottom left quadrant of the plot contains variables that represent feelings of depression. The nine emotions in this region are:

- Lonely (1)

- $\quad$ Scared (2)

- $\quad$ Upset (5)

- Worried (9)

- $\quad$ Depressed (10)

- $\operatorname{Sad}(15)$

- Confused (17)

- $\quad$ Miserable (18)

- Unhappy (22)

Case 30: The participant reports being homeless and not being physically or mentally well in herself. She reports drinking and attempting to commit suicide but being taken to hospital by an ambulance. When taken to hospital she reports having a flashback that reminded her of her son being taken away from her as a baby, she reports lashing out 
Emotions and Crime

at hospital staff as she felt vulnerable due to the fact she had been stripped of her clothes. The participant reports being confused about the situation and feeling extremely lonely, scared, upset, worried and depressed.

Distress. The top left quadrant of the SSA includes emotions indicative of distress. The four emotions that are present in this region are:

- Annoyed (13)

- Angry (14)

- $\quad$ Irritated (19)

- Pointless (25)

Case 23: In this situation, the participant reports confronting the father of the male that had raped her little sister aged 14. She reports feeling extremely distressed, angry, irritated and annoyed at the father and blamed him for her sister's trauma. During the assault feelings of pointlessness were also reported.

Elation. The bottom right of the quadrant can be described as emotions related to elation. There are seven emotions in this region:

- $\quad$ Pleased (6)

- $\quad$ Exhilarated (3)

- Enthusiastic (11)

- $\quad$ Excited (16)

- Courageous (23) 
Emotions and Crime

- Delighted (21)

- Confident (4)

Case 34: The participant describes being addicted to drugs and committing a burglary to 'flog' the items to score. She describes targeting a property she knew would be easy to access. She reports feeling pleased, excited, exhilarated, courageous, confident and delighted during the commission of the crime.

Calm. The area in the top right of the SSA plot can be described as feelings of calmness. There are five emotions in this region:

- $\quad$ Safe (8)

- Calm (7)

- Thoughtful (12)

- Relaxed (20)

- Contented (24)

Case 29: In this offence, the participant reports driving under the influence of alcohol, she said she had been at the cinema and then went to the pub with friends. She reported during the crime feeling calm, confident and thoughtful.

\section{Themes of Emotions and Russell's Circumplex (1997)}

The second objective outlined was to examine whether emotions experienced during the commission of crimes would capture the range of emotions reflected in Russell's Circumplex model (1997). As discussed four distinct themes could be identified, these reflect those highlighted by Russell (1997): elation, calm, distress and 
Emotions and Crime

depression. Furthermore, as can be highlighted in Figure 2. emotions plotted to the left of the plot clearly link to feelings of displeasure including items such as annoyed and unhappy. Whereas emotions to the right, are much more pleasurable with emotions such as pleased and relaxed. The clear division of emotions can be paralleled with Russell's dominant axis of pleasure-displeasure, thus indicating the relevance to experience of crime.

The distinct division along the axis of pleasure-displeasure indicates that participants report experiences as either pleasant or unpleasant with very little difference between these two extremes. Thus, indicating a more bipolar structure as opposed to the circular structure of emotions. Figure 2. displays the SSA plot with Russell's (1997) themes applied for each regional interpretation.

\section{Internal Reliability of Emotion Themes}

Within the four emotion themes outlined it is suggested each is representative of a distinct theme. To examine the reliability coefficient for each emotional theme Cronbach's alpha was utilised. The emotions and the $\alpha$ for each theme are given in Table

5. The alpha coefficient for depression was .91 , for distress .79 and for elation .81 indicating a high degree of association between variables in each of the themes. The calm theme reported alpha was .67, suggesting a lower level of reliability. Further inspection highlights if the variable 'thoughtful' was removed the alpha score would increase .71, suggesting the internal consistency for this item is not as reliable as the others. Variance may be due to the items phrasing, however previous research suggests that for exploratory research an alpha level of .60 is adequate (Nunnelly, 1970). Thus, as this is the first study of this kind amongst women offenders the level is acceptable. To prevent 
Emotions and Crime

future issues with these items, examination on larger samples could be utilised to explore whether the alpha level for the variables increased, if this did not affect reliability level then for further research these items could be removed.

\section{INSERT TABLE 5 HERE}

\section{Testing the Framework}

Whilst the SSA analysis highlights four emotionally meaningful themes, it does not categorise the offenders themselves. An offender may experience emotions from more than just one SSA region, although because these regions represent emotionally distinct themes, it would be expected the majority of emotions felt, would fall into one particular region. To explore this further each of the 128 cases were individually examined to ascertain whether they could be assigned to a specific theme on the basis of the emotions they reported whilst committing their crimes. Each case was given a percentage score to determine the proportion of variables present for each of the four themes, elation, calm, distress and depression.

The criteria for assigning a case to a theme was that the dominant theme had to have a greater number of variables than the other themes. Percentages were used rather than actual numbers as each of the four themes did not have an equal number of variables attributed to them $($ Elation $=7$, Calm $=5$, Distress $=4$, Depression $=9$ ). Cases were not classified if they contained an equal number of variables for more than two themes, or if there was no predominant theme. A case was considered a hybrid if it contained the same number of variables for each theme. 
Emotions and Crime

Utilising this method, the prevalence of each emotional theme is displayed in Table 6. A total of $92.2 \%$ (118 out of 128) cases could be classified into one of the four emotional themes. Exploring cases further, the most prevalent emotional theme employed in this sample was depression with $46.9 \%$ (60 cases), followed by distress $38.3 \%$ (49 cases). Only $3.9 \%$ (5 cases) reported the elation theme, $3.1 \%$ (4 cases) calm theme and $4.7 \%$ were either a hybrid of depressed-distress (6 cases) or nonclassifiable $3.1 \%$ (4 cases).

\section{INSERT TABLE 6 HERE}

\section{DISCUSSION}

Emotions and Crime. The first objective of this research was to establish whether the structure of emotions experienced by women when committing crimes could be differentiated in terms of different emotion themes e.g. elation, calm, distress, depression. The second objective was to determine whether Russell's (1997), circumplex structure of emotions could be applied to women offender's criminal experiences. Both objectives were met, and in line with the circumplex theory, the SSA analysis (Figure. 2), supported the distinction of clear dominant dimensions of pleasure and displeasure. This in turn allowed for identification of four emotional themes: elation, calm, distress and depression. Thus, suggesting that emotional experiences in criminal contexts are a result of normal emotional functioning. Findings are consistent with previous research that suggest emotions are at the centre of every individuals processing and are responsible for all communications individuals undertake (Jarymowicz, 2012; Oatley \& Jenkins, 
Emotions and Crime

1996). Similarly, the dimensionality demonstrated supports previous studies suggesting emotions with similar themes are related to each other in a systematic manner rather than being independent (Mehrabian \& Russell, 1974; Russell, 1979; Daley et al, 1983).

However, it is important to note that although the circular order of emotions was represented the SSA analysis does indicate that women's experience of crime may be more bipolar than the usual range of emotions particularly in regards to the pleasuredispleasure axis. This is representative of previous research that has outlined strong distinctions between pleasure and displeasure in male offenders' criminal emotional experiences (Canter \& Ioannou, 2004; Ioannou, 2006). It is also clear in this sample that women offenders report significantly more unpleasant criminal emotional experiences (depression and distress) in comparison to pleasant emotions (calm and elation). Combining negative emotional themes; depression, distress and depresseddistressed accounts for $89.9 \%$ (115 cases) of the sample. Leaving only $7 \%$ (9 cases) reporting more positive emotional variables calm and elation. Overall this differs from previous research amongst men, (Ioannou, 2006), which reported all four themes more equally, representing both positive and negative emotional experiences of crime. Whereas for women their emotional experiences were overwhelmingly negative. This is in line with previous research that indicates women report more powerless emotions such as sadness in comparison to men (Fischer, Rodriguez, Vianen \& Manstead, 2004).

\section{Implications of the Research}

Results of the current study highlight important factors in aiding understanding of emotional experiences amongst women offenders, and present practical and theoretical implications. Whilst only currently exploratory, the findings from this study offer an 
Emotions and Crime

alternative theoretical framework for exploring criminal behaviour. Moreover, this study highlights experiences during offending are an extension of normal emotional behavioural rather than some atypical characteristic of it. Thus, highlighting that knowledge and models that are beneficial in the general population, particularly in regards to emotional experiences, can also be applicable to criminal populations.

Practically, the results also offer real world benefits for therapeutic and law enforcement agencies. Understanding how individuals felt and thought during the commission of their crime can be utilised to enhance understanding, build rapport and implement more targeted and beneficial treatment and sentencing options. Results provide an initial grounding relating to types of emotional regulation each individual struggles with, and as a result specialised and tailored therapeutic interventions could be developed. Developing targeted programmes could have a wide range of benefits including increased emotional control, wellbeing, rehabilitation, and reduced recidivism rates.

\section{Limitations and Future Research}

As outlined this study is the first exploration of emotional experience amongst women offenders, and whilst exploratory, there are certain factors that need to be highlighted that may impact generalisability. Although a reasonable sample size given the nature of the study, an increased number of participants would strengthen and validate the findings further. Similarly, most of the women (89.1\%) were White, it is important to highlight that whilst results offer a promising framework for exploration, this same pattern may not be replicated amongst other cultures. Likewise, there was no control in 
Emotions and Crime

relation to varying ages of the women, this could also have a confounding impact on results as emotional responses may vary throughout women's criminal careers.

Another limitation is the range of crime types reported, whilst there is a variety, there are key crimes such as murder that are not represented in this sample, thus results can only be applied to reported crimes within this sample. Furthermore, women were simply asked to recall a crime they remembered well. There were no stipulations in relation to crime type, variations of crime types, time between recalled crimes or total number of crimes. Thus, as a result it is important to highlight potential confounding variables relating to these variations such as possible desensitisation, memory decay/variation and discrepancies between crime types/number of crimes in relation to emotional experience.

As with all social science research there are certain individual factors that also need to be acknowledged such as socially desirable answering. Whilst precautions were taken to insist on honest reporting, this was ultimately up to participants. Arguably however, whether truthful or not, results are still representative of how individuals viewed themselves and their experience, so this is still important. Similarly, subjectivity of understanding the scales and questions was ultimately dependent on individual interpretation. For example, one participants definition of 'angry' compared to 'annoyed' may vary to another's, so limitations relating to consistency of classification need to be acknowledged. Issues relating to recall need to be highlighted, as there were no stipulations (other than the crime was remembered clearly and recalled accurately) in relation to the time when the crime was committed, and type of crime reported there may be discrepancies in memory and selection bias that need to be acknowledged. For 
Emotions and Crime

example, a crime committed in the last couple of months is likely to be remembered more clearly than one from 10 years ago, similarly emotions associated with a theft offence are likely to vary to one of violence and selection of the variations of these was not controlled for.

To address some of these limitations further explorations could be undertaken. Firstly, larger cross-cultural samples could be obtained to examine patterns further amongst varying groups to determine whether research findings can be generalised to the whole women offender population. Similarly, more extensive explorations could be undertaken to examine individuals' emotional experiences across a wide variety of crimes, both similar e.g. one robbery in comparison to another, but also comparison of different crimes such as theft to murder, to examine whether there are dominant emotional themes across crime type or whether these vary depending on the offence. Likewise, further investigations relating to the number of crimes and varying factors relating to these such as comparisons between single, first and numerous offences could be explored to examine the potential impact such factors have in regard to emotional response. Similarly, further research regarding factors relating to onset of crime such as personal background, life experiences, explorations relating to variations in age, personality characteristics, criminal thinking styles, mental health diagnoses and substance misuse issues could be explored in line with individuals' emotional experiences to establish further patterns of offending behaviours, and identify factors related to propensity to crime. Furthermore, clearer examinations relating to memory recall could be explored. For example, setting stricter time parameters such as offences committed within the last twelve months could be examined in comparison to older offences to see if there are any variations from the current research. 
Emotions and Crime

\section{Conclusion}

To conclude, appreciation and understanding of the phenomenological experiences women encounter when engaged in crime is crucial. Allowing women to report emotional experiences relating to their offences can be helpful in addressing core feelings underlying their crimes and be useful in helping women gain greater insight into why they offend to utilise this knowledge to prevent a further life of crime. Findings offer a promising starting point for future examination of women offenders and can be used to help inform future policies and practice. 
Emotions and Crime

\section{References}

Abelson, R. P., \& Sermat, V. (1962). Multidimensional scaling of facial expressions. Journal of Experimental Psychology, 63 (6), 546-554. doi:10.1037/h0042280

Åkerström, M. (1999). Looking at the squares: Comparisons with the square Johns. In P. Cromwell (Ed.), In their own words: Criminals on crime (2nd ed., pp. 23 - 31). Los Angeles, USA: Roxbury Publishing Company.

Averill, J. R. (1975). A semantic atlas of emotional concepts. Catalog of Selected Documents in Psychology, 5, 330-421

Andrews, D. A., \& Bonta, J. (2010). The psychology of criminal conduct (5th ed.). Cincinnati, $\mathrm{OH}$ : Anderson Publishing.

Andrews, D. A., Guzzo, L., Raynor, P., Rowe, R. C., Rettinger, L. J., Brews, A., \& Wormith, J. S. (2012). Are the major risk/need factors predictive of both female and male reoffending? A test with the eight domains of the level of service/case management inventory. International Journal of Offender Therapy and Comparative Criminology, 56, 113-133. doi:10.1177/0306624X10395716

Bernasco, W. (2010). Offenders on offending: Learning about crime from criminals. Cullompton: Willan.

Blagden, N. J., Winder, B., Thorne, K., \& Gregson, M. (2011). 'no-one in the world would ever wanna speak to me again': An interpretative phenomenological analysis into convicted sexual offenders' accounts and experiences of maintaining and leaving denial. Psychology, Crime \& Law, 17(7), 563-585. doi:10.1080/10683160903397532 
Emotions and Crime

Bloom, B., Owen, B., \& Covington. (2003). Gender-responsive strategies: Research, practice, and guiding principles for women offenders. Washington, DC: National Institute of Corrections, US Department of Justice.

Borg, I., \& Lingoes, J. (1987). Multidimensional similarity analysis. New York: Springer-Verlag.

Brebner, J. (2003). Gender and emotions. Personality and Individual Differences, 34 (3), 387-394. doi:10.1016/S0191-8869(02)00059-4

Canter, D. (1984). Facet theory: Approaches to social research. New York: SpringerVerlag.

Canter, D., \& Ioannou, M. (2004). Criminals' emotional experiences during crimes. International Journal of Forensic Psychology, 1 (2), 71-81. Retrieved from: http://eprints.hud.ac.uk/8199/1/CriminalEmotions.pdf

Carney, D. R., \& Colvin, C. R. (2010). The circumplex structure of affective social behavior. Social Psychological and Personality Science, 1(1), 73-80. doi:10.1177/1948550609353135

Chesney-Lind, M. \& Pasko, L. (2004). The Female Offender-Girls, Women and Crime (2nd ed.).Thousand Oaks, California: Sage.

Chaplin, T. M., \& Aldao, A. (2013). Gender differences in emotion expression in children: A meta-analytic review. Psychological Bulletin, 139(4), 735-765. doi:10.1037/a0030737 
Emotions and Crime

Cook, K. J. (2016). Has criminology awakened from its "Androcentric slumber"? Feminist Criminology, 11(4), 334-353. doi:10.1177/155708511660437

Corston, J. (2007). The Corston Report: A Report by Baroness Jean Corston of the Review of Women with Particular Vulnerabilities in the Criminal Justice System. London: Home Office.

Covington, S.S. \& Bloom, B.E. (2006). Gender-responsive treatment and services in correctional settings. In Leedes (Ed.). Inside Out: Women, Prison and Therapy (p9-33). Binghamton, NY: Hayworth Press.

Cross, C. (1998). The experience of crime: Associated roles and emotions. Unpublished BSc thesis. University of Liverpool, UK.

Daly, K. (1992). Women's pathways to felony court: Feminist theories of lawbreaking and problems of representation. Review of Law and Women's Studies, 2(11), 1152.

Daly, E. M., Lancee, W. J., \& Polivy, J. (1983). A Conical model for the taxonomy of emotional experience. Journal of Personality and Social Psychology, 45 (2), 443457. doi:10.1037/0022-3514.45.2.443

de Vogel, V., de Vries-Robbe, M.,Van Kalmthout, W. \& Place, C. (2012). The Female Additional Manual (FAM). Additional guidelines to the HCR-20 for assessing risk for violence in women. Van der Hoeven: Stiching.

Facchin, F., \& Margola, D. (2016). Researching lived experience of drugs and crime: A phenomenological study of drug-dependent inmates. Qualitative Health Research, 26(12), 1627-1637. doi:10.1177/1049732315617443 
Emotions and Crime

Feldman, L. A. (1995). Variations in the circumplex structure of emotion. Personality and Social Psychology Bulletin, 21 (8), 806-817. doi: 10.1177/014616729 5218003

Feldman Barrett, L., \& Russell, J. A. (1998). Independence and bipolarity in the structure of affect. Journal of Personality and Social Psychology, 74 (4), 967984. doi:10.1037/0022-3514.74.4.967

Fisher, G.A., Heise, D.R., Bohrnstedt, G.W., \& Lucke, J.F. (1985). Evidence for extending the Circumplex model of personality trait language to self-reported moods. Journal of Personality and Social Psychology, 49 (1), 233-242. doi:10.1037/0022-3514.49.1.233

Fischer, A. H., Rodriguez, P. M., van Vianen, A. E. M., \& Manstead, A. S. R. (2004). Gender and culture differences in emotion. Emotion, 4 (1), 87-94. doi:10.1037/1528-3542.4.1.87

Fontanari, J. F., Bonniot-Cabanac, M., Cabanac, M., \& Perlovsky, L. I. (2012). A structural model of emotions of cognitive dissonances. Neural Networks : The Official Journal of the International Neural Network Society, 32, 57-64. doi:10.1016/j.neunet.2012.04.007

Gendreau, P. C., Smith, P., \& French, S. (2006). The theory of effective correctional intervention: Empirical status and future directions. In Cullen, F., Wright, J., Coleman, M. (Eds.), Taking stock: The status of criminology theory (pp. 419446). Piscataway, NJ: Transaction Press.

Guttman, L. (1954). A new approach to factor analysis: The radex. In Lazarsfield (Ed.), Mathematical thinking in the social sciences. New York, USA: Free Press. 
Emotions and Crime

Guttman, L. (1968). A General nonmetric technique for finding the smallest coordinate space for a configuration of points. Psychometrica, 33, 469-506.

Indermaur, D. (1993). Offenders' perspectives on property crime. In P. Cromwell (Ed), In their own words: Criminals on crime ( $1^{\text {st }}$ ed.). Los Angeles, USA: Roxbury Publishing Company.

Ioannou, M. (2006). Hero or villain? Criminals' experience of crime. (PhD thesis). University of Liverpool, Liverpool.

Ioannou, M., Canter, D., \& Youngs, D. (2017). Criminal narrative experience: Relating emotions to offence narrative roles during crime commission. International Journal of Offender Therapy and Comparative Criminology, 61(14), 1531-1553. doi:10.1177/0306624X15625991

Izard, C.E. (1972). Patterns of emotions. New York, USA: Academic Press.

Jackson-Roe, K., Murray, C., \& Brown, G. (2015). Understanding young offenders' experiences of drinking alcohol: An interpretative phenomenological analysis. Drugs: Education, Prevention and Policy, 22(1), 77-85. doi:10.3109/09687637.2014.973371

Jarymowicz, M. (2012). Understanding human emotions. Journal of Russian and East European Psychology, 50 (3), 9-25. doi:10.2753/RPO1061-0405500301

Jones, N. J., Brown, S. L., Wanamaker, K. A., \& Greiner, L. E. (2014). A quantitative exploration of gendered pathways to crime in a sample of male and female juvenile offenders. Feminist Criminology, 9(2), 113-136. doi:10.1177/1557085113501850 
Emotions and Crime

Katz, J. (1988). Seductions of crime: Moral and sensual attractions in doing evil. USA: Basic Books.

Katz, J. (1999). How emotions work. Chicago, USA: the University of Chicago Press.

Langton, C.M. \& Marshall, W.L. (2000). "The role of cognitive distortions in relapse prevention programs". In Remaking relapse prevention with sex offenders, Edited by: Laws, D.R., Hudson, S.M. and Ward, T. 167-186. Thousand Oaks, CA: Sage.

Lingoes, J. (1973). The Guttman-Lingoes non-metric program series. MA Thesis. University of Michigan.

Loizou, G., \& Karageorghis, C. I. (2015). Construction and validation of the circumplex model of affect with english and greek athletic samples. International Journal of Sport and Exercise Psychology, 13(3), 224-242. doi:10.1080/1612197X.2015.1039693

Mehrabian, A., \& Russell, J.A. (1974). A verbal measure of information rate for studies in environmental psychology. Environment and Behaviour, 6 (2), 233-252. doi: $10.1177 / 001391657400600205$

Murray, K. (1998). An investigation into the experience of crime: A Multidimensional scalogram analysis of the emotions and roles experienced while committing an offence. Unpublished BSc thesis. University of Liverpool, UK.

Norberg, C. (2012). Male and female shame: A corpus-based study of emotion. Corpora, 7 (2), 159-185. doi:10.3366/cor.2012.0025

Nunnelly, J. C. (1970). Psychometric Theory (2 ${ }^{\text {nd }}$ ed.). New York: McGraw Hill. Oatley, K., \& Jenkins, J.M. (1996). Understanding emotions. Oxford, UK: Blackwell. 
Emotions and Crime

Oldale, K. (1997). The experience of crime. Unpublished BSc thesis. University of Liverpool, UK.

Plutchik, R. (1962). The emotions: Fact, theories and a new model. New York, USA: Random House.

Plutchik, R. (2000). Emotions in the practice of psychotherapy: Implications of affect theories. Washington, DC, USA: American Psychological Association.

Remington, N. A., Fabrigar, L. R., \& Visser, P. S. (2000). Re-examining the circumplex model of affect. Journal of Personality and Social Psychology, 79 (2), 286-300. doi: 10.1037//0022-3514.79.2.286

Rossegger, A., Wetli, N., Urbaniok, F., Elbert, T., Cortoni, F., \& Endrass, J. (2009). Women convicted for violent offenses: Adverse childhood experiences, low level of education and poor mental health. BMC Psychiatry, 9 (1), 81-81. doi:10.1186/1471-244X-9-81

Russell, J.A. (1978). Evidence of convergent validity on the dimensions of affect. Journal of Personality and Social Psychology, 36 (10), 1152 - 1168. doi:10.1037/0022-3514.36. 10.1152

Russell, J.A. (1980). A Circumplex model of affect. Journal of Personality and Social Psychology, 39 (6), 1161 - 1178. doi:10.1037/h0077714

Russell, J.A. (1983). Pancultural aspects of the human conceptual organisation of emotions. Journal of Personality and Social Psychology, 45 (6), 1281 - 1288. doi:10.1037/0022-3514.45.6.1281 
Emotions and Crime

Russell, J.A. (1997). How shall an emotion be called? In R. Plutchik \& H.R. Conte (Eds.), Circumplex models of personality and emotions (pp. 205-220). Washington, D.C, USA: American Psychological Association.

Russell, J.A., \& Mehrabian, A. (1977). Evidence for a three-factor theory of emotions. Journal of Research in Personality, 11 (3), 273-294. doi: 10.1016/00926566(77)90037

Salisbury, E.J. (2007). Gendered pathways: An empirical investigation of women offenders' unique paths to crime. Unpublished doctoral dissertation, University of Cincinnati.

Schlosberg, H. (1941). A scale for the judgment of facial expressions. Journal of Experimental Psychology, 29 (6), 497 - 510. doi:10.1037/h0061489

Schlosberg, H. (1954). Three dimensions of emotion. Psychological Review, 61 (2), 8188. doi: $10.1037 / \mathrm{h} 0054570$

Scott, M. S., \& Dedel, K. (2006). Street prostitution. US Department of Justice, Office of Community Oriented Policing Services.

Shye S. (1978). Theory construction and data analysis in the behavioural sciences. Philadelphia: Jossey-Bass.

Tziner, A.E. (1987). The facet analytic approach to research and data processing. New York: Peter Lang.

Watson, D., \& Tellegen, A. (1985). Toward a consensual structure of mood. Psychological Bulletin, 98 (2), 219-235. doi:10.1037/0033-2909.98.2.219 
Emotions and Crime

Wright, R.T., Decker, S.H., Redfern, A.K., \& Smith, D.L. (1999). A snowball's chance in hell: Doing fieldwork with active residential burglars. In P.Cromwell (Ed.), In their own words: Criminals on crime $\left(2^{\text {nd }}\right.$ ed., pp. $\left.1-7\right)$. Los Angeles, USA: Roxbury Publishing Company. 
Emotions and Crime

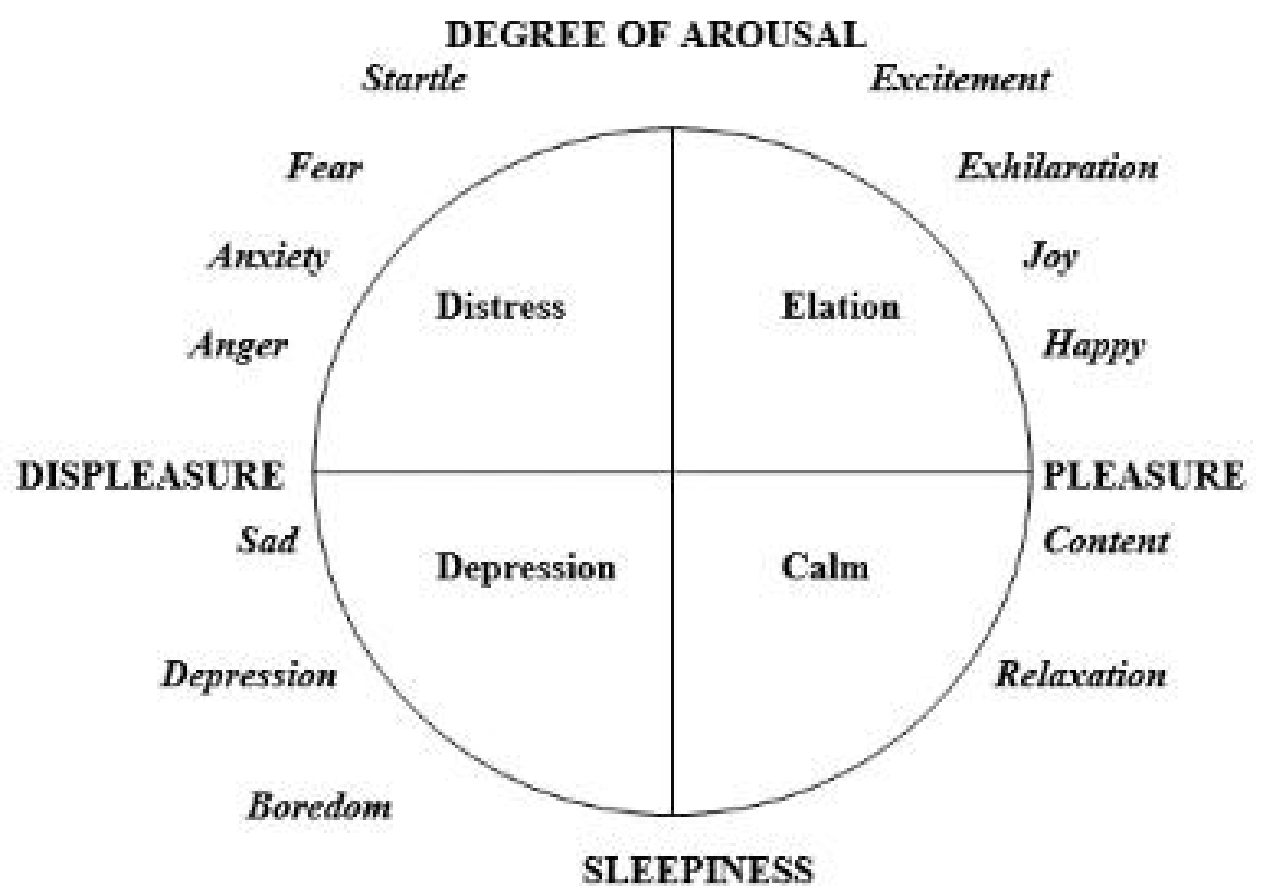

Figure 1. Russell's (1997) Circumplex of Emotions 
SSA OF EMOTIONS WITH REGIONAL INTERPRETATIONS

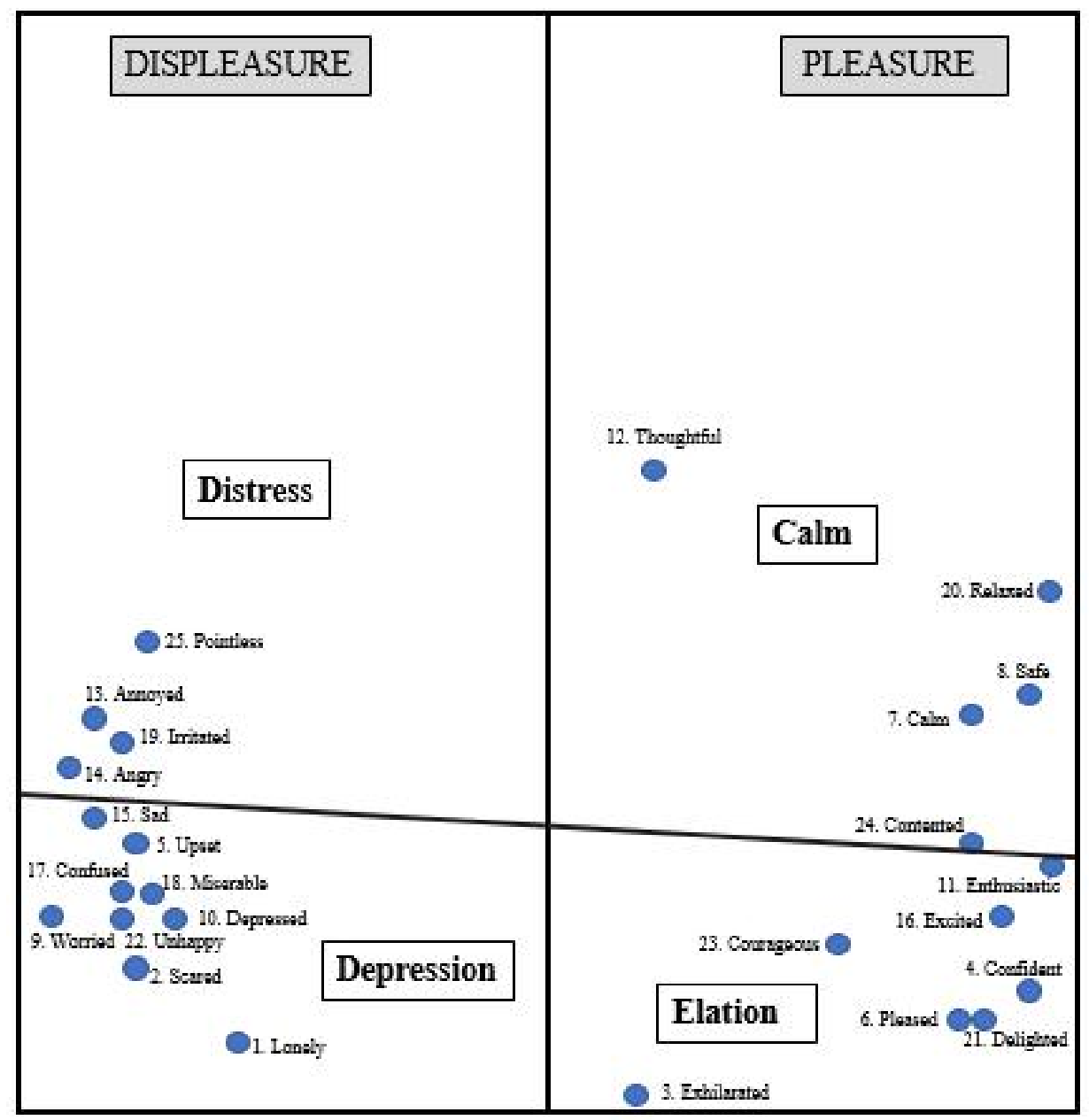

Figure 2.1 by 2 Projection of the Two-Dimensional Smallest Space Analysis of Emotions with Regional Interpretations.

Coefficient of Alienation $=0.10149$ 
Emotions and Crime

Table 1.

Participants' Ethnicity

\begin{tabular}{lc}
\hline Ethnicity & Percentage of Sample \\
\hline White & 89.10 \\
Pakistani & 2.30 \\
Indian & 2.30 \\
Black- African & 1.60 \\
Black-Caribbean & 0.80 \\
Bangladeshi & 0.80 \\
Other & 3.10 \\
\hline
\end{tabular}


Emotions and Crime

Table 2.

Number of Participants Interviewed For Each Offence Type

\begin{tabular}{lclc}
\hline Type of Offence & No. & Type of Offence & No. \\
& Offenders & & Offenders \\
Violence & 36 & Driving Offences & 6 \\
Theft & 34 & Drunk and Disorderly & 4 \\
Drug Offences & 9 & Robbery & 3 \\
Burglary & 7 & Criminal Damage & 5 \\
Arson & 6 & Receiving Stolen Goods & 1 \\
Fraud & 7 & Neglect of Animals & 1 \\
Sex Offence (Adult) & 1 & Neglect of Children & 2 \\
Truancy of Child & 1 & Attempted Infanticide & 1 \\
Cruelty to Children & 1 & Sex Offence (Child) & 3 \\
& & &
\end{tabular}


Emotions and Crime

Table 3.

Number of Convictions

\begin{tabular}{lc} 
No. of Convictions & Percentage of Sample \\
\hline None & 3.90 \\
Less than 10 & 60.20 \\
$10-20$ & 5.50 \\
$21-30$ & 7.00 \\
$31-40$ & 7.80 \\
$41-50$ & 2.30 \\
More than 50 & 13.30 \\
\hline
\end{tabular}


Emotions and Crime

Table 4.

The Emotions and Analysis Labels

\begin{tabular}{|c|c|c|}
\hline $\begin{array}{l}\text { Question } \\
\text { Number }\end{array}$ & Full Question & $\begin{array}{c}\text { Analysis } \\
\text { label }\end{array}$ \\
\hline 1 & I felt lonely & Lonely \\
\hline 2 & I felt scared & Scared \\
\hline 3 & I felt exhilarated & Exhilarated \\
\hline 4 & I felt confident & Confident \\
\hline 5 & I felt upset & Upset \\
\hline 6 & I felt pleased & Pleased \\
\hline 7 & I felt calm & Calm \\
\hline 8 & I felt safe & Safe \\
\hline 9 & I felt worried & Worried \\
\hline 10 & I felt depressed & Depressed \\
\hline 11 & I felt enthusiastic & Enthusiastic \\
\hline 12 & I felt thoughtful & Thoughtful \\
\hline 13 & I felt annoyed & Annoyed \\
\hline 14 & I felt angry & Angry \\
\hline 15 & I felt sad & Sad \\
\hline 16 & I felt excited & Excited \\
\hline 17 & I felt confused & Confused \\
\hline 18 & I felt miserable & Miserable \\
\hline 19 & I felt irritated & Irritated \\
\hline 20 & I felt relaxed & Relaxed \\
\hline 21 & I felt delighted & Delighted \\
\hline 22 & I felt unhappy & Unhappy \\
\hline 23 & I felt courageous & Courageous \\
\hline 24 & I felt contented & Contented \\
\hline 25 & I felt pointless & Pointless \\
\hline
\end{tabular}


Emotions and Crime

Table 5.

Scales of Emotions Themes (with Alpha if Item Deleted in Parentheses)

\section{THEME}

$\begin{array}{lll}\text { ELATION CALM } & \text { DISTRESS DEPRESSION }\end{array}$

\begin{tabular}{lllll} 
ITEMS & Pleased (.78) & Safe (.56) & Annoyed (.69) & Lonely (.91) \\
& Exhilarated (.81) & Calm (.56) & Angry (.67) & Scared (.90) \\
& Enthusiastic (.79) & Thoughtful (.71) & Irritated (.75) & Upset (.90) \\
& Excited (.76) & Relaxed (.64) & Pointless (.82) & Worried (.90) \\
& Courageous (.79) & Contented (.57) & & Depressed (.89) \\
& Delighted (.79) & & & Sad (.90) \\
& Confident (.79) & & & Confused (.90) \\
& & & & Miserable (.89) \\
& & & & Unhappy (.89) \\
$\begin{array}{l}\text { No. of } \\
\text { Items }\end{array}$ & 7 & 5 & & 9 \\
\hline $\begin{array}{l}\text { Cronbach's } \\
\text { Alpha }\end{array}$ & .81 & .67 & & \\
\hline
\end{tabular}


Emotions and Crime

Table 6.

Distribution of Cases Across Emotion Themes

Narrative Theme

Depression

Distress

Hybrid Depression-Distress

Elation

Calm

Non-Classifiable

\section{Number of Cases}

$60(46.9 \%)$

$49(38.3 \%)$

$6(4.7 \%)$

$5(3.9 \%)$

$4(3.1 \%)$

$4(3.1 \%)$ 